\title{
INDICADORES DE EXITO DE CIUDADES RIBEREÑAS (Y LA COMPARACIÓN CON BARRANQUILLA) ${ }^{1}$
}

Artículo de Reflexión - Recibido: 10 de Febrero de 2016 - Aceptado:20 de Mayo de 2016

\section{Liliana Ramos ${ }^{2}$}

Fundación para la Investigación, Desarrollo e Innovación I+D+I. Barranquilla, Colombia. liliana@fundacionidi.org

Para citar este artículo / to reference this article:

Ramos, L. (2016). Indicadores de exito de ciudades ribereñas (y la comparación con barranquilla). Módulo Arquitectura CUC, Vol.17 No 1, 133-144

\section{Resumen}

En el presente artículo se realiza una reflexión acerca de los cuales son los elementos característicos en el crecimiento y desarrollo urbano de ciudades con borde a ríos y que de cierta manera han sido exitosas desde el punto de vista de competitividad y rehabilitación ambiental. El objetivo primordial es el de presentar esas características urbanas que han desarrollado esas ciudades ribereñas, las cuales generan unos indicadores comunes que permitan estandarizar la competitividad de las ciudades con borde a rio.

\section{Palabras clave}

Competividad, crecimiento urbano, borde, ciudad ribereña

\footnotetext{
1 Articulo producto de la investigación Elementos Característicos de ciudades ribereñas terminada en 2015 2 Investigadora y Contadora Publica especialista en tributaria y magister en administración.
} 


\title{
SUCCESS INDICATORS OF RIBEREÑAS CITIES (AND THE COMPARISON WITH BARRANQUILLA)
}

\begin{abstract}
In this article a reflection on which are the characteristic elements on growth and urban development of cities with rivers edge and that in some way have been successful from the point of view of competitiveness and environmental is performed. The primary objective is to present these urban characteristics that have developed these coastal cities, which generate common indicators to standardize the competitiveness of cities with a river edge.
\end{abstract}

\section{Keywords}

Competitiveness, urban growth, edge, riverside city 


\section{Introduccion}

La relación entre un rio y el desarrollo de la ciudad ha prevalecido en la historia sin existir independencia entre la ubicación geográfica de un lugar y la búsqueda de abastecimiento de agua. Es por esto que el desarrollo y fundación de una ciudad siempre va caracterizada por la trasformación del sitio que contiene un cauce y roda de rio. De ahí que los accidentes geográficos del cauce de un rio se convierten en rasgos permanentes en la estructura de la ciudad. "El valor de esta relación es dinámico como la corriente del caudal de agua. Se transforma y se modifica de acuerdo al desarrollo social" (Rojas, 2009). La sociedad humana debe una parte crucial de su desarrollo y surgimiento a los ríos, los cuales han estado presentes en todas las etapas del desarrollo y la historia humana y han influido de manera importantísima en el proceso de asentamiento urbano. "La ciudad nació entre los ríos" (Mesopotamia)" De ahí que a lo largo de la historia gran número de ciudades se fundaban al borde o cerca de ríos y en lugares muy específicos del mismo, como islas en el rio, en su desembocadura y hasta $Y$ en la bifurcación o encuentro de dos ríos, entre otros (Kostof, 1992). Además, las actividades agrícolas y las industriales hasta muy poco tiempo, eran extremadamente dependientes de fuentes de agua cercanas. De igual manera el comercio dependía de los ríos ya que eran las vías de transporte que permitían abarcar grandes distancias en zonas de la civilizaciones tanto occidental como la oriental, permaneciendo así durante gran parte de la historia hasta la revolución industrial (Silva, Serdoura y Pinto, 2006).

Las ciudades se han esparcido por todo el mundo convirtiéndose en lugar esencial de la vida humana y debido al desarrollo industrial el mundo se está urbanizando cada vez más. En 1900, sólo 160 millones de personas, una décima parte de la población mundial vivían en las ciudades, pero para la década del 2000, más de la mitad del mundo ya estaba viviendo en áreas urbana. Mientras que la población urbana en todo el mundo crece, de igual manera crecen los problemas sociales y ambientales sobre todo sobre los recursos hídricos y los ríos se han afectado todavía más (Simsek, 2012).

En el caso específico de la ciudad de Barranquilla, la cual tiene un borde con el rio Magdalena de $22 \mathrm{Km}$ de longitud, entre el puente Pumarejo y la desembocadura del mismo en 
Bocas de Ceniza. (Alvarado, 2007), la discusión sobre el desarrollo y las intervenciones sobre el borde del rio ha sido durante más de veinte años motivo de apreciaciones de diferente índole, ya que los intereses industriales no van acordes con los intereses sociales y ambientales. Esto ha traído una serie de situaciones problemáticas que han terminado por incidir directamente en la degradación del espacio habitable, desmejorando la funcionalidad de la ciudad y la calidad de vida de los habitantes del sector (López, 2014).

Las transformaciones que ha experimentado la ciudad de Barranquilla, responden a factores políticos, sociales, culturales, económicos; Estas realidades locales, regionales, nacionales y universales, han desarrollado en esta sociedad eventos como: la devaluación de la moneda colombiana, la inflación, las migraciones de campesinos del campo a la ciudad, como respuesta a la crisis social que a su vez es el resultado de los malos manejos políticos-económicos y que ha fomentado la profunda brecha entre el ente institucional y las soluciones positivas a esta crisis consolidándose de esa manera, la guerra civil colombiana, esta guerra ha fraccionado y destruido el equilibrio de nuestra sociedad, dándose de esa manera, la aparición del desplazado en la ciudad. Por otro lado, la pésima planificación de las políticas educativas, dan como resultado un individuo que no guarda respeto ni por la sociedad, ni por sí mismo, menos por los valores que merecen los distintos componentes urbanos, en este caso el Espacio Público (Ramos, 1992).

El Río Magdalena ha sido un elemento estructurante del desarrollo económico, relacionado con la movilidad y el transporte de carga pero al mismo tiempo la sedimentación, la cual requiere de gran inversión para su mantenimiento, la construcción del Puente Pumarejo sobre el Río Magdalena en la ciudad de Barranquilla, con una altura baja (16 metros), lo cual no permite el tránsito de barcos o naves marítimas en su recorrido un poco más adentro del territorio, donde están los centros industriales como PIMSA (Parque Industrial de Malambo S.A.),entre otras cosas han ocasionado la baja competitividad del puerto fluvial y otro aspecto muy importante: el gran auge y desarrollo de la explotación minera en Colombia, relacionada con el carbón mineral, el cual, luego de su extracción es transportado por vía terrestre también hacia otros los muelles del país (López, 2014). 


\section{Indicadores}

\section{Sistema Integrado rio y ciudad}

Existe una dependencia entre el cauce del rio, su ronda y su delta con el desarrollo urbano de la ciudad a su borde. El rio en un principio limita, condiciona y se convierte en eje estructurante de la urbe. En la actualidad es posible que esa relación predominante del rio sobre su ciudad borde pueda cambiar y sea el crecimiento de la ciudad que moldee el cauce del rio o su borde. Generalmente en esta relación se produce un fraccionamiento de la unidad marcada por el cauce del río. Se crean distintos sectores o fragmentos urbanos, los cuales adquieren un carácter particular que responde a la superposición espacial de la estructura de la ciudad construida sobre el río. Esta fragmentación sectorial urbana se articula con elementos de la traza urbana general como puentes o puntos focales sobre el borde $u$ orilla del rio, marcando distintos imaginarios urbanos y ritmos de vida específicos. Según Rojas (2009) "El río pierde su sentido original longitudinal y continuo para ahora participar de los fragmentos espaciales, y sus condiciones específicas, marcados por la secuencia continua de las actividades urbanas" (Rojas, 2009).
Esta relación física rio y ciudad no debe verse solo desde uno de los lados o como elementos individuales sino como ente en conjunto o un solo organismo. El borde del rio por lo menos en la parte que limita con la urbe no puede ser disociada de la ciudad que atraviesa. Se convierte en un sistema a escala regional, reflejando la interacción en ciudades y territorios. El rio refuerza el sistema urbano generando una identidad y dando coherencia espacial (Silva, Serdoura y Pinto, 2006).

Este sistema rio y ciudad posee propiedades jerárquicas dependiendo del tamaño y ancho del rio. Una ciudad con amplias zonas o superficies abiertas cerca del rio, pueden ser grandes espacios públicos o grandes vías urbanas puede significar que la ciudad ha valorado su relación y ha interpretado su función dentro del sistema rio y ciudad. Existen indicadores que ayudan a la comprensión de la mayor o menor grado de integración entre la ciudad y el río. Estos indicadores, entre otros son: diferencia de altura entre la orilla del rio y la ciudad, dimensión urbana, la duración de la orilla del río y el ancho del río, superficie del cuerpo de agua y el número de cruces. Estos elementos 
son causas y consecuencias del tipo de ciudad y su configuración que se creó en el borde del rio. que se formó, por ejemplo la presencia de cruces de ríos es esencial para asegurar la conectividad entre los bancos con gran influencia sobre el nivel de la estructura de la ciudad de la integración (Silva, Serdoura y Pinto, 2006). así como la pendiente media en cada orilla y la relación entre la pendiente más empinada y la orilla más plana, elemento de su importancia para la accesibilidad al cauce del río y en la forma de atravesarlo, influyendo en la configuración de la ciudad (Veiga, 2004) y en la densidad poblacional así como en la capacidad de la ciudad de equilibrar su desarrollo en las dos orillas del río o, por el contrario, se concentrado en una sola orilla.

El área de contacto de forma longitudinal entre las zonas pobladas de la ciudad y el río, comparada con el área urbana total de la ciudad, se considera un buen indicador de proximidad e interrelación entre la ciudad y el río. Esto describe la forma en que la ciudad ocupa (o no) la angosta franja de 150 metros en todo el largo de ambas orillas del río, lo que se define como Waterfront y dependiendo de su desarrollo, crecimiento e importancia mayor nivel de integración existe conjuntamente con una mayor diversidad de usos del suelo a lo largo de las riberas de los ríos (Silva, Serdoura y Pinto, 2006).

\section{Competitividad}

En la actualidad todas las ciudades del mundo luchan por ser competitivas y posicionarse en el circuito internacional del capital. De esta manera la mayor parte de las políticas urbanas impulsadas, tanto por autoridades locales como regionales y nacionales, tienen como objetivo crear las condiciones para acelerar el crecimiento económico dándole preferencia a las actividades relacionadas con la construcción, el comercio y servicios financieros (Fuentes y Orellana, 2012).

"La búsqueda de competitividad para las ciudades necesita que se emprendan acciones para crear una imagen que les permita una proyección internacional acorde con el posicionamiento deseado" (Paz, Tkachuc y Fernández, 2014). Las ciudades con borde de rio no son la excepción. Los ríos con bordes urbanos proporcionan distintas fuentes de suministro de agua potable mejorando la calidad de vida 
tanto en lo económico como en lo social. Crear una imagen diferente y atrayente de las zonas urbanas es una de las premisas más importantes que se apoya en la relación rio y ciudad con la rehabilitación de los bordes. Prácticas urbanas de rehabilitación de ríos ayudan a hacer de las ciudades que tienen sistemas urbanos eficientes. Una de las principales iniciativas de las ciudades con borde a ríos competitivas es la de concebir la orilla del rio como un producto. Esto significa que se le da un potencial y un valor urbano alto, lo que da lugar a una idea y visión paisajística de alta calidad atrayendo gran número de turistas. Desligar el borde de rio que limita con la ciudad de la función industrial y portuaria genera intervenciones, rehabilitaciones y recomposiciones urbanas dando paso a espacios ribereños que no estaban en el radar del poblador obteniendo un potencial turístico especial (Paz, Tkachuc y Fernández, 2014). Los espacios ribereños, antes considerados como terrenos de desechos, son reconvertidos en un espacio público integrando usos hoteleros, gastronómicos, comerciales, de entretenimientos y de paseos (Paz, Tkachuc y Fernández, 2014).

\section{Fachadas Fluviales}

Las ciudades con borde a rio y que son exitosas invierten en el concepto de fachadas fluviales. Gran número de ciudades dan la espalda a sus ríos y es de suma importancia revertir este hecho. Tanto en Europa como en Estados Unidos y varios países del oriente asiático han iniciado procesos recientes de aproximación a sus ríos. Las intervenciones tradicionales en relación con los bordes de los ríos que limitan con las ciudades obedecen a necesidades sectoriales y son generalmente canalizaciones, rectificación de cauces, muelles, desvíos y embovedados, entre otros; por otro, las ciudades más exitosas tienden a mejorar la estética urbana valorizando la fachada fluvial generando proyectos de paseos de ribera, regulación de los frentes de edificación al río, malecones, infraestructura de ocio entre otras. Esto significa que, a pesar del predominio relativo de las lógicas sectoriales, las actuaciones de mejora de las riberas y de las fachadas fluviales en ciudades han dado como resultado una integración decisiva, superior y de gran impacto en componentes del paisaje urbano (Monclús, 2002). 


\section{Borde ribereño como Patrimonio}

Tomar en borde ribereño como parte del patrimonio histórico, cultural, arquitectónico y urbano de la ciudad es clave para el correcto funcionamiento del sistema rio y ciudad. En esos bordes se pueden encontrar antiguas construcciones con alto valor arquitectónico que funcionaban como depósitos de mercancías o antiguas instalaciones aduaneras, también es posible encontrar estructuras sumergidas como restos de naufragios, barcos encallados, trozos o fragmentos de antiguas embarcaciones náuticas. Esto se concibe como patrimonio de tipo arqueológico y de gran valor cultural, que no sólo incluye todos los vestigios de la existencia humana, sino que abarca los lugares relacionados con cualquier manifestación de su actividad. Dicho patrimonio, es esencial debido a que contribuye a la creación de la identidad de la ciudad y al sentido de pertinencia de la población, así como un atractivo turístico y de ocio. Esto valoriza el sentido histórico de la orilla del rio en todo el tramo que limita con la urbe. (Paz, Tkachuc y Fernández, 2014)

Otro elemento que se introduce al es el del arte público, satisfaciendo la necesidad del objeto monumental como elemento fundamental de hacer ciudad y de preservar el espacio público. El arte en el espacio público colocado en las zonas de riberas se convierte en elemento distintivo de la ciudad, y se desarrolla como un tipo de decoración urbana. Para lograr esto es necesario un conjunto de intervenciones estéticas sobre el territorio y una gran inversión que da como resultado la apropiación social e individual del espacio ribereño. El arte público facilita la comunicación entre el habitante y el espacio público ribereño, la idea es que los ciudadanos tengan el control sobre la estética de su lugar o de su ciudad. (Paz, Tkachuc y Fernández, 2014)

\section{Conclusiones}

Las ciudades ribereñas tienen una ventaja muy marcada para lograr el éxito, si realmente se relacionan bien con el rio con el cual bordean. Aunque el éxito no se debe medir teniendo en cuenta solo los factores económicos de inversión financiera, o de simples intervenciones urbanísticas como la construcción de un parque junto al agua, o de rehabilitar infraestructuras antiguas o cambiar edificios obsoletas por imágenes artificiales 
importadas; por el contrario el éxito de una ciudad ribereñas depende de las transformaciones de sus waterfronts visto como un conjunto de compromisos fundamentados en una interrelación profunda y efectiva en todos los niveles entre ciudad y río visto como un sistema. (Galimberti, 2014) La mayor cantidad de intervenciones en las orillas de los ríos que bordean ciudades han sido de carácter de control de inundaciones con canales, diques y presas y se sabe que los ríos generan un gran impacto en las ciudades en términos de aumento de población y desarrollo urbano, (Simsek, 2012) lo que genera que esas intervenciones ya no son suficientes y no caben en la idea de una ciudad contemporánea exitosa.

En la actualidad los gobiernos locales cumplen un rol de gran importancia para la implementación de paquetes de proyectos que logren establecer la relación rio y ciudad como un sistema urbano único y eficiente con programas que adopten estrategias de competitividad, de valorizar no solo económicamente sino patrimonialmente y culturalmente y de rehabilitación de las riberas de los ríos urbanos. (Simsek, 2012). Estos mecanismos deben ser establecidos y coordinados institucionalmente ya que son intervenciones complejas que garanticen las inversiones correspondientes y la sostenibilidad de las mismos. (Monclús, 2002)

Así mismo es de suma importancia manejar el concepto de fachada fluvial y borde reconociendo toda la complejidad de la construcción del espacio circundante de un límite, en este caso la orilla del rio, las cuales cuentan con morfologías no definidas y que sean entendidas como lugares de interacción de aspectos sociales, económicos y culturales, donde lo urbano y lo natural se mezclan y se relacionan y que a menudo son territorios difusos identificado por combinaciones de características y fenómenos, generando a lo largo de sí actividades urbanas. (Toro, 2005)

Todas las ciudades ribereñas relativamente exitosas tienen en común la acción de la sociedad local que guían las rehabilitaciones de los bordes de ríos o waterfronts, participando activamente frente a las transformaciones que ocurrirán en sus frentes fluviales, logrando defender su patrimonio ambiental y cultural evitando las intervenciones de promotores inmobiliarios inescrupulosos. De igual manera sin una correcta intervención y planificación publica consensuada 
en todos los niveles estatales no se podría lograr el objetivo de recuperar los frentes fluviales y lograr fachadas fluviales adecuadas. (Galimberti, 2014).

Cabe anotar que otro hecho común es la intervención crítica y permanente de los actores académicos y políticos entre otros con el fin de reflexionar sobre si una ciudad ribereña es exitosa o no, luego de las intervenciones en sus riberas. Puesto que se tiende a confundir las acciones positivas de gestión de nuevos territorios con tendencias de desvinculación de la identidad local por una idea genérica globalizada como es el caso de la museificación. Por supuesto que para poder recuperar el valor sociocultural de estos bordes fluviales, es necesario comprenderlos de manera integral (Galimberti, 2014).

Por su parte en palabras de Alvarado (2007) "Barranquilla, la principal ciudad de Colombia en la costa Caribe, ha dependido históricamente de su ubicación con respecto al río Magdalena y al mar Caribe, y en función de ellos y de su lejanía de los principales centros de producción nacional, su desarrollo económico ha de su crecimiento le dio la espalda al río, pero es indudable que Barranquilla creció en función del río; lo que le dio una fisonomía de acuerdo con sus necesidades como área urbana. Barranquilla pasó de ser el puerto más importante de Colombia, a un insignificante asentamiento ribereño en una localización estratégica. La importancia comercial de Barranquilla radica en su situación favorable, siendo estación de tránsito forzoso del $70 \%$ del tráfico comercial del país (Palacio, 2012), lo que le da un potencial enorme para convertirse en ciudad ribereña exitosa. Para la Presidencia de la República de Colombia (2013) es económicamente factible que se desarrolle la navegación fluvial entre Barranquilla y Cartagena hasta Caucasia, con una longitud de 1.195 $\mathrm{km}$. Y continua explicando que "el río Magdalena tiene una capacidad potencial máxima de transporte de 550 millones de toneladas al año, como vía navegable, lo que equivale a siete veces la carga actualmente se moviliza por carretera, estimada en 81,0 millones de toneladas. De las propuestas consideradas para reactivar la navegabilidad del río Magdalena, la más favorable permitiría incrementar el flujo actual de 2,1 millones a seis millones de toneladas al año, en el transcurso del 
primer año. A su vez, los puertos de Barrancabermeja, Puerto Berrío, La Dorada y Puerto Salgar estarían en capacidad de superar el movimiento de carga actual del área portuaria de Barranquilla" (República de Colombia, Presidencia la República, 2013). Esto permitiría la competitividad junto con la construcción del nuevo puente Pumarejo y demolición del antiguo. Pero es extremadamente importante plantear un plan que logre crear una visión analítica y critica en la ciudadanía y en la administración local sobre el estudio de borde del rio y la integración del mismo con la trama urbana para convertirlo en un sistema real (López, 2014):

"Los valores ambiental, social y cultural del Río Magdalena constituyen las bases para una mayor integración urbana Ciudad-Río que revierta, con el tiempo, la escasa vinculación del ciudadano con este importante recurso" (López, 2014).

\section{Referencias}

Alvarado, M. (2007). Barranquilla como vamos. En Entorno natural de 17 ciudades de Colombia. Barranquilla: Universidad del Norte.
Kostof, S. (1992). The city Assembled: The elements of urban form through history. Londres: Thames \& hudson Ltd.

López, J. (2014). Eco renovación urbana del borde de la ciudad de Barranquilla que limita con el rio Magdalena. Módulo Arquitectura CUC, 255-271.

Monclús, F. (2002). Ríos, ciudades, parques fluviales, corredores verdes. Rios y Ciudades: Aportaciones para la recuperación (p. 12 - 31). Zaragoza: Institución «Fernando el Católico.

Palacio, B. (2012). Barranquilla y el Período Republicano Mercantil. Módulo Arquitectura CUC, 145 169.

Paz, S., Tkachuc, C. y Fernández, G. (2014). La reestructuración de los espacios ribereños y su patrimonio. Aportes desde el marketing urbano. Habitat. Metropolis.

República de Colombia. Presidencia la República. (2013). Río Grande. Bogotá, D.C.: Cormagdalena.

Ramos, J. (1992). El problema de los grupos desplazdados por la violenci: una vision depertamental y barrial. Investigacion y desarrollo, 32. 
Rojas, A. (2009). El Rio y la Ciudad. Bitacora. Urnao Territorial, 41-44.

Silva, J., Serdoura, F. y Pinto, P. (2006). Urban Rivers as Factors of Urban (Dis)integration. 42nd ISoCaRP Congress 2006 (p. 1-14). Lisboa: Estambul.
Simsek, G. (2012). Urban River Rehabilitation as an Integrative Part of Sustainable. 48th ISOCARP Congress 2012 (p. 1 -12). Perm: 48th ISOCARP Congress 2012.

Veiga, C. (2004). Urbanizacao em Encosta: O caso da alt de Coimbra. Coimbra: Universidade de Coimbra. 